\title{
Severe Chronic Isosporosis: An Early Clinical Indicator of Immunosuppressive Disease in a Patient With HTLV-1
}

\author{
Luke Simon Olivera Yuhico ${ }^{\mathrm{a}, \mathrm{c}}$, Britta Denman ${ }^{\mathrm{b}}$, Donald Blair ${ }^{\mathrm{b}}$
}

\begin{abstract}
Isospora belli is known to cause diarrhea in immunocompromised patients. We report a case of severe isosporosis in a patient with previously undiagnosed human T-lymphotropic virus type I (HTLV-1) and T-cell lymphoma. This illustrates the disease association of isosporosis and HTLV-1, establishing severe isosporosis as a possible early indicator of immunosuppression.
\end{abstract}

Keywords: Isospora belli; Diarrhea; HIV; HTLV; Immunosuppression

\section{Introduction}

A 44-year-old Sudanese immigrant was transferred from an outside hospital with a nine month history of severe diarrhea. Her symptoms included 10 - 20 bowel movements of profuse watery stool per day, with associated abdominal cramping, increased flatulence, nausea, vomiting and a reported 105 pound weight loss. She denied fever, chills, hematemesis, hematochezia, melena or mucus in her stool.

She emigrated to the United States ten years prior to presentation, without subsequent international travel. Her social history was notable for daily alcohol intake until the onset of her diarrhea. She denied tobacco use and intravenous drug abuse. There was no history of unprotected intercourse with multiple partners. She denied contact with individuals with

\footnotetext{
Manuscript accepted for publication July 9, 2012

${ }^{a}$ Department of Medicine, SUNY Upstate Medical University, Syracuse, New York, 13210, USA

${ }^{\mathrm{b}}$ Division of Infectious Diseases, Department of Medicine, SUNY Upstate Medical University, Syracuse, New York, 13210, USA

${ }^{\mathrm{c}}$ Corresponding author: Luke Simon Olivera Yuhico, Mailing address: 142 Beresford Lane, Minoa, NY 13116, USA.

Email: luke_yuhico@yahoo.com
}

doi: $10.4021 / \mathrm{jmc} 775 \mathrm{w}$ similar symptoms or other illnesses. She had no past surgical history, history of malignancy or of other gastrointestinal comorbid conditions.

\section{Hospital course}

The patient was admitted to University Hospital where she was found to be severely cachectic with weight at $45.4 \mathrm{~kg}$ (100 pounds); blood pressure $88 / 55$; pulse rate, 80 - 100; respiratory rate, 18 ; oxygen saturation, $98 \%$ on room air; and maximum temperature, $37.5{ }^{\circ} \mathrm{C}$. Physical examination revealed mild diffuse abdominal tenderness with no evidence of acute abdomen.

Outside records revealed various evaluations with negative results: stool examination for Giardia and Cryptosporidium, serology for hepatitis A, B, C and HIV. Abnormalities found included: fatty change of the liver by ultrasound; hepatic hemangioma and slightly dilated bowel loops by computerized tomography (CT) scan; gastritis by upper endoscopy; and mild villous blunting of the colonic mucosa by colonoscopy. Empiric treatment with cholestyramine, rifaximin, alosetron and proton pump inhibitors had also been initiated, however these did not ameliorate her presenting symptoms. A celiac diet had also yielded no clinical improvement.

On admission, laboratory evaluation revealed hyponatremia with a serum sodium of $128 \mathrm{mmol} / \mathrm{L}$ and a non-anion gap metabolic acidosis. Urinalysis was within normal limits. Albumin was low at $2.5 \mathrm{~g} / \mathrm{dL}$, with a total protein of $5.8 \mathrm{~g} /$ dL. Transaminases were elevated at ALT, 104 U/L; AST, 64 $\mathrm{U} / \mathrm{L}$. Additional liver function tests revealed an elevated alkaline phosphatase, $187 \mathrm{U} / \mathrm{L}$; total bilirubin, $0.3 \mathrm{mg} / \mathrm{dL}$; and direct bilirubin, $0.2 \mathrm{mg} / \mathrm{dL}$. Lipase was within normal limits, 9 U/L; Urine Beta HCG was negative. Complete blood count demonstrated anemia with a hemoglobin of $10.5 \mathrm{~g} / \mathrm{dL}$ and hematocrit $30.8 \%$. The white blood cell count was $10.3 \mathrm{~K} / \mu \mathrm{L}$ with 64\% neutrophil, 21\% lymphocyte, and 1\% eosinophil. Serology for viral hepatitis A, B, C was negative.

Forty-eight hour stool collection measured $6,700 \mathrm{~mL}$ $(7.17 \mathrm{~kg})$ watery, non-bloody stool. Multiple stool tests revealed Isospora belli. Stools were negative for microsporidium, giardia, Entamoeba histolytica, cryptosporidium, 
Clostridium difficile, salmonella, shigella, campylobacter, aeromonas, plesiomonas, or E. coli 0157 . Given the severity of disease, evaluation for possible etiologies of an immunocompromised state was obtained. HIV 1/ HIV 2 antibody and HIV Group O were negative, 5-Hydroxyindoleacetic acid, vasoactive intestinal peptide, serotonin level, anti-endomysial antibodies, tissue transglutaminase, Strongyloides stercoralis antibodies, Entamoeba histolytica antibodies, thyroid stimulating hormone and cosyntropin tests were all unremarkable. Gastrin level was elevated at $466 \mathrm{pg} / \mathrm{mL}$, however this was attributed to her chronic PPI therapy. Serology was positive for human T-lymphotropic virus type 1 (HTLV-1) and negative for HTLV-2. Review of outside biopsies and imaging studies revealed no evidence of gastrointestinal malignancy or tuberculosis.

Intravenous rehydration, total parenteral nutrition and gluten and milk-free enteral nutrition were initiated. Octreotide, paregoric, loperamide and ondansetron were intermittently used for symptomatic management. As no other etiology for her chronic diarrhea could be found, she was treated for Isospora belli with oral trimethoprim-sulfamethoxazole (TMP/SMX).

Within two days of initiation of antibiotic therapy, improvement was noted. Frequency of stools decreased from over 10 movements/24hours to 4 movements/24hours, and increased in consistency. In 7 days, her stool frequency was decreased to one or two formed stools per day. Abdominal pain completely resolved. Patient's weight rose to $60.45 \mathrm{~kg}$ (133 lbs), an increase of $15 \mathrm{~kg}$ by the time of discharge from the hospital.

She was followed in outpatient clinic due to her HTLV1 positivity. In one month, she was noted to develop new bilateral inguinal lymphadenopathy on physical exam. CT scan revealed extensive axillary, mediastinal, hilar and retroperitoneal adenopathy. Skeletal survey later showed multiple lytic lesions in her skull, hip, left radius and right humerus. Lymph node biopsy eventually revealed non-Hodgkins Tcell lymphoma and she was referred to oncology for management.

\section{Discussion}

Isospora belli is a protozoal pathogen that became more prevalent in the United States (US) with the HIV disease epidemic. Infections with this pathogen are also more likely to be found in foreign-born patients [1]. This pathogen has been notorious to cause chronic diarrhea and weight loss. It is usually linked to a state of immunosuppression, most commonly HIV [2]. It is the initial AIDS-defining illness in about 2-3\% of African AIDS patients and is present in $7-20 \%$ of African AIDS patient with chronic diarrhea [3]. Non-HIV associated Isospora belli has been described in other immunosuppressive states, such as Hodgkins disease, HTLV-1 associated adult T-cell leukemia, non-Hodgkins lymphoma, and chronic corticosteroid therapy [4-7].

This case illustrates that Isospora belli diarrhea can represent the first manifestation of immunodeficiency in an HTLV-1 infected patient. Symptom resolution occurred immediately on initiating therapy with TMP/SMX, which is known to produce treatment response in management of this infection, further qualifying Isospora belli as its sole etiology $[8,9]$.

HTLV-1 is a retrovirus associated primarily with adult T-cell leukemia (ATL) and HTLV-1 associated myelopathy/ tropical spastic paraparesis (HAM/TSP). Infection is lifelong, but $95 \%$ remain asymptomatic throughout life with only a $1-4 \%$ cumulative lifetime risk to develop ATL or HAM/TSP [10]. It is also associated with increased susceptibility to severe forms of strongyloidiasis due to a reduction in IL-4, 5, 13 and the parasitic IgE response, which comprise the body's defense mechanism against Strongyloides stercoralis [11]. Stool examinations to screen for Strongyloides stercoralis have been recommended for early detection and treatment initiation prior to hyperinfection [12]. On initial presentation, although testing positive for HTLV-1, this patient had not shown any manifestations of these entities and was presumed immunocompetent at the time.

Through this case, we highlight that severe isosporosis may be utilized as a sole early indicator of possible immunodeficiency, particularly in HTLV-1 positive patients. In this patient, it was likely the earliest sign of HTLV-1 associated immunodeficiency and the development of adult T-cell lymphoma. We recommend screening for HTLV-1 infection in patients with chronic isosporosis, and subsequent close monitoring and evaluation for immunosuppressive diseases in HTLV-1 positive individuals. Likewise, we also recommend screening for Isospora belli infection in HTLV-1 positive individuals for early initiation of therapy.

Although chronic diarrhea is notable in immunodeficiency-associated Isosopora belli infection, to our knowledge, this is the first report of severe chronic isosporosis presenting prior to the diagnosis of the primary immunosuppressive disease etiology.

\section{Acknowledgement}

No external source of financial support was needed for this manuscript. The authors do not have any association that may pose a conflict of interest.

\section{Authors' Contributions}

All authors have contributed significantly to the production of this manuscript. All authors have seen and have approved the manuscript. 


\section{References}

1. Sorvillo FJ, Lieb LE, Seidel J, Kerndt P, Turner J, Ash LR. Epidemiology of isosporiasis among persons with acquired immunodeficiency syndrome in Los Angeles County. Am J Trop Med Hyg. 1995;53(6):656-659.

2. Arora DR, Arora B. AIDS-associated parasitic diarrhoea. Indian J Med Microbiol. 2009;27(3):185-190.

3. Minnaganti, V. Isosporiasis. Available at http://emedicine.medscape.com/article/ 219776-overview. Accessed 3 August, 2010.

4. Peng CY, Tsai W. Isospora belli infection in a patient with Hodgkin's disease: report of a case. J Formos Med Assoc. 1991;90(3):260-263.

5. Kawano F, Nishida K, Kurisaki H, Tsukamoto A, Satoh M, Sanada I, Shido T, et al. [Isospora belli infection in a patient with adult T-cell leukemia]. Rinsho Ketsueki. 1992;33(5):683-687.

6. Resiere D, Vantelon JM, Bouree P, Chachaty E, Nitenberg G, Blot F. Isospora belli infection in a patient with non-Hodgkin's lymphoma. Clin Microbiol Infect. 2003;9(10):1065-1067.

7. Malik S, Samantaray JC, Bagga A, Das A. Refractory isosporiasis. Indian J Pediatr. 2005;72(5):437-439.

8. Pape JW, Verdier RI, Johnson WD, Jr. Treatment and prophylaxis of Isospora belli infection in patients with the acquired immunodeficiency syndrome. N Engl J Med. 1989;320(16):1044-1047.

9. Verdier RI, Fitzgerald DW, Johnson WD, Jr., Pape JW. Trimethoprim-sulfamethoxazole compared with ciprofloxacin for treatment and prophylaxis of Isospora belli and Cyclospora cayetanensis infection in HIV-infected patients. A randomized, controlled trial. Ann Intern Med. 2000;132(11):885-888.

10. Szczypinska EM, Wallace M, Wainscoat B, Salas CM, Rich J. Human T-cell Lymphotropic Viruses. Available at http://emedicine.medscape.com/article/219285-overview. Accessed 22 July 2010

11. Porto MA, Muniz A, Oliveira Junior J, Carvalho EM. [Clinical and immunological consequences of the association between HTLV-1 and strongyloidiasis]. Rev Soc Bras Med Trop. 2002;35(6):641-649.

12. Carvalho EM, Da Fonseca Porto A. Epidemiological and clinical interaction between HTLV-1 and Strongyloides stercoralis. Parasite Immunol. 2004;26(1112):487-497. 